\title{
Abandono escolar no Ensino de Jovens e Adultos na Escola Abraham Lincoln, Medicilândia, Pará
}

\author{
School abandonment in the Education of Youth and Adults at Abraham Lincoln School,
} Medicilândia, Pará

Abandono escolar en la Educación de Jóvenes y Adultos en la Escuela Abraham Lincoln, Medicilândia, Pará

\section{Resumo}

O objetivo é analisar os aspectos ligados ao abandono escolar no Programa de Educação de Jovens e Adultos (EJA) na escola Abraham Lincoln, Medicilândia, Pará, no período de 2003 a 2017, analisando as causas do abandono e as dificuldades pedagógicas apontadas pelos docentes e gestores. Trata-se de pesquisa quali-quantitativa, em que foram entrevistados alunos, docentes e gestores desta unidade de ensino e feita a análise dos relatórios finais das turmas de Educação de Jovens e Adultos nesse período. Foi verificado que dos 5670 matriculados no período 2003 a 2017 , 2696 estudantes desistiram dos estudos, ou seja, o abandono escolar atingiu 47,5\% ao longo de 15 anos, sendo que o maior índice de abandono foi em 2004, com 66,5\%, representado por trezentos e dois alunos desistentes, destacando também os anos 2006, 2012, 2014 e 2015. Verificou-se que as causas mais comuns dos alunos que residem na área urbana é a dificuldade de conciliar com o trabalho e a baixa motivação dos mesmos, e os da área rural, além do trabalho, foi mencionada a falta de transporte público regular para se deslocarem para a cidade. Outro ponto crítico para o aprendizado e permanência dos estudantes está na deficiência do suporte didático e pedagógico, e no uso de metodologias não diferenciadas, que não consideram a diversidade do público, quanto ao gênero, modo de vida e falta de apoio no âmbito familiar.

Palavras-chave: Educação do campo; Escolas do campo; Ensino.

\begin{abstract}
The objective is to analyze the aspects related to school dropout in the Youth and Adult Education Program (EJA) at Abraham Lincoln School, Medicilândia, Pará, from 2003 to 2017, analyzing the causes of dropout and the pedagogical difficulties pointed out by teachers and managers educational. This is a quali-quantitative research, in which students, teachers and managers of this teaching unit were interviewed and the final reports of the Youth and Adult Education classes were analyzed during this period. It was found that of the 5670 enrolled in the period 2003 to 2017,2696 students dropped out of studies, that is, school dropout reached $47.5 \%$ over 15 years, with the highest dropout rate being in 2004, with $66.5 \%$, represented by three hundred and two students who dropped out, also highlighting the years 2006, 2012, 2014 and 2015. It was found that the most common causes of students residing in urban areas is the difficulty of reconciling with work and the low motivation of the students. and those in rural areas, in addition to work, the lack of regular public transport to travel to the city was mentioned. Another critical point for students' learning and permanence is the lack of didactic and pedagogical support, and the use of non-differentiated methodologies, which do not consider the diversity of the public, in terms of gender, livelihood and lack of family support.
\end{abstract}

Keywords: Rural education; Countryside schools; Teaching.

\section{Resumen}

El objetivo es analizar los aspectos relacionados con la deserción escolar en el Programa de Educación de Jóvenes y Adultos (EJA) de la Escuela Abraham Lincoln, Medicilândia, Pará, de 2003 a 2017, analizando las causas de la 
deserción y las dificultades pedagógicas señaladas por docentes y gerentes. Se trata de una investigación cualicuantitativa, en la que se entrevistó a estudiantes, docentes y directivos de esta unidad didáctica y se analizaron los informes finales de las clases de Educación de Jóvenes y adultos durante este período. Se encontró que de los 5670 matriculados en el período 2003 al 2017, abandonaron los estudios 2696 estudiantes, es decir, la deserción escolar alcanzó el 47,5 \% en 15 años, siendo la tasa de deserción más alta en el año 2004, con el 66,5 \%, representada por tres ciento dos estudiantes que desertaron, destacando también los años 2006, 2012, 2014 y 2015. Se encontró que las causas más comunes de los estudiantes que residen en zonas urbanas es la dificultad de conciliación con el trabajo y la baja motivación de los estudiantes. los de las zonas rurales, además del trabajo, se mencionó la falta de transporte público regular para trasladarse a la ciudad. Otro punto crítico para el aprendizaje y la permanencia de los estudiantes es la falta de apoyo didáctico y pedagógico, y el uso de metodologías no diferenciadas, que no consideran la diversidad del público, en cuanto a género, modos de vida y falta de apoyo familiar.

Palabras clave: Educación Rural; Escuelas del Campo; Enseñanza.

\section{Introdução}

Serão tratados nesse artigo questões relativas ao processo abandono escolar, que em muitas vezes levam à evasão definitiva de estudantes da Educação de Jovens e Adultos (EJA). Entendendo que a evasão escolar ocorre quando um aluno abandona a escola ou reprova em determinado ano letivo e no ano seguinte não efetua sua matrícula para dar continuidade aos estudos. E abandono escolar é relativo às taxas de rendimento dentro de um ano letivo, desse modo, em uma situação de abandono, os indivíduos iniciam o ano frequentando a escola e, no decorrer do mesmo ano, deixam de frequentá-la após uma data de referência, podendo ser calculado pela diferença entre o número de matrículas iniciais e finais de um determinado ano letivo. É um problema acarretado por uma série de fatores que podem estar ligados a questões sociais diversas e a falta de políticas educacionais para conter esses processos (Santos et al., 2019).

A escolha dessa temática teve como origem a observação realizada em turmas de EJA nos estágios supervisionados realizados no terceiro ano do curso de Licenciatura em Educação do Campo ${ }^{1}$, da Universidade Federal do Pará, do expressivo número de alunos que abandonam seus estudos na escola Abraham Lincoln, localizada na sede do município de Medicilândia, que atende também a estudantes camponeses que saem diariamente de suas localidades para terem acesso à educação.

A partir do contexto camponês e educacional, e ao longo das reflexões proporcionadas pelo curso em Educação do Campo, direcionado desde o primeiro momento para conhecer as escolas e as comunidades dos educandos, e diversas questões ligadas às práticas docentes e ao processo de ensino-aprendizagem, vislumbra-se construir uma educação do campo diferenciada, que contemple os interesses das populações do campo e os seus projetos familiares e coletivos (Arroyo et al.,2011). Caldart (2009) expõe que:

[...] sua natureza e seu destino estão profundamente ligados ao destino do trabalho no campo e, consequentemente, ao destino das lutas sociais dos trabalhadores e da solução dos embates de projetos que constituem a dinâmica atual do campo brasileiro, da sociedade brasileira, do mundo sob a égide do capitalismo em que vivemos. E ainda que 'muitos não queiram', esta realidade exige posição (teórica sim, mas sobretudo prática, política) de todos os que hoje afirmam trabalhar em nome da Educação do campo (Caldart, 2009, p. 36-37).

Os estágios supervisionados realizados no programa de Educação de Jovens e Adultos (EJA) ofereceram elementos novos para a formação, devido ser uma modalidade de ensino fundamental e médio oferecida para alunos que estão com defasagem em seus estudos, ou seja, a idade não corresponde à escolaridade instituída como padrão. Foi nesse estágio que se deparou com a desmotivação e desistência de estudantes, e também com as limitações para se ter processos adequados de

\footnotetext{
${ }^{1} \mathrm{O}$ curso de Licenciatura em Educação do Campo vinculado à Faculdade de Etnodiversidade, Campus de Altamira, foi criado em 2014 e visa formar educadores para atuarem junto às populações ribeirinhas, quilombolas e camponesas; o mesmo já ofertou turmas em nove municípios da região do Xingu e rodovia Transamazônica, além do município de Gurupá na região do Marajó, no estado do Pará.
} 
ensino e de aprendizagem, incluindo questões ligadas à prática e à formação docente para atuar nas especificidades do campo e de suas populações (Tenório et al., 2019; Tardif, 2002; Tardif, 2004).

A Lei de Diretrizes e Bases da Educação n 9.304 de 1996, em seu artigo 37, parágrafo $1^{\text {o }}$, traz que a educação de jovens e adultos será destinada àqueles que não tiveram acesso ou continuidade de estudos no ensino fundamental e médio na idade apropriada. E que os sistemas de ensino assegurarão gratuitamente aos jovens e aos adultos, que não puderam efetuar os estudos na idade regular, oportunidades educacionais apropriadas, consideradas as características do alunado, seus interesses, condições de vida e de trabalho, mediante cursos e exames. Ficando assim sob obrigação de estados e municípios oferecerem essa modalidade de ensino.

A resolução de $\mathrm{n}^{\circ}$ 01, de 05 de julho de 2000, do Conselho Nacional de educação (CNE), que estabelece as Diretrizes Curriculares Nacionais para a Educação de Jovens e Adultos, em seu artigo $5^{\circ}$, parágrafo único, diz o seguinte:

Como modalidade destas etapas da Educação Básica, a identidade própria da Educação de Jovens e Adultos considerará as situações, os perfis dos estudantes, as faixas etárias e se pautará pelos princípios de equidade, diferença e proporcionalidade na apropriação e contextualização das diretrizes curriculares nacionais e na proposição de um modelo pedagógico próprio, de modo a assegurar:

I - quanto à equidade, a distribuição específica dos componentes curriculares a fim de propiciar um patamar igualitário de formação e restabelecer a igualdade de direitos e de oportunidades face ao direito à educação;

II- quanto à diferença, a identificação e o reconhecimento da alteridade própria e inseparável dos jovens e dos adultos em seu processo formativo, da valorização do mérito de cada qual e do desenvolvimento de seus conhecimentos e valores;

III - quanto à proporcionalidade, a disposição e alocação adequadas dos componentes curriculares face às necessidades próprias da Educação de Jovens e Adultos com espaços e tempos nos quais as práticas pedagógicas assegurem aos seus estudantes identidade formativa comum aos demais participantes da escolarização básica.

Portanto, essa modalidade de ensino requer um olhar diferenciado em relação ao público atendido, com o planejamento didático-pedagógico, curricular e de infraestrutura que considerem o perfil dos educandos, como os trabalhadores do campo ou da cidade, já que em sua maioria é de pessoas que estão enquadradas no processo de distorção idade-série, pessoas que trabalham durante o dia, pessoas com faixa etária acima de 18 anos e que querem dar prosseguimento aos seus estudos para atender expectativas diversas.

A partir do questionamento sobre as causas que levam ao abandono escolar pelos estudantes camponeses, esse trabalho tem como objetivo geral o de analisar os aspectos ligados ao abandono escolar na Educação de Jovens e Adultos (EJA) na escola Abraham Lincoln, Medicilândia, Pará. E tem como objetivos específicos: a) discutir os dados referentes ao abandono escolar no período de 2003 a 2017; b) analisar as causas do abandono escolar a partir das informações de estudantes desistentes, moradoras da cidade e do campo, e c) refletir sobre as dificuldades ligadas às práticas docentes voltada para a EJA.

\section{Metodologia}

Este trabalho tem abordagem de pesquisa quali-quantitativa, pela qual se buscou conhecer as particularidades, experiências individuais e os pontos de vista por meio de entrevistas semiestruturadas orientadas por roteiros previamente elaborados, e a utilização em conjunto de dados quantitativos (Minayo, 2008; Gerhardt et al.,2009). Para isso, foi realizado um estudo de caso sobre a EJA (Yin, 2015) na principal escola que oferta o ensino fundamental por meio do programa EJA no município de Medicilândia, a Escola Abraham Lincoln. Foram também utilizados dados secundários provenientes de pesquisa nos arquivos da escola, de relatórios finais e o quadro de estatísticas desde o primeiro ano de implantação da Educação de Jovens e Adultos, contemplando o período de 2003 a 2017. Esses dados foram sistematizados e tratados no Excel.

Foram realizadas dez entrevistas semiestruturadas com alunos desistentes, com escolha de uma amostra tendo como critérios os para atender as diferenças de sexo, estado civil, idade, empregados ou não, se moram na cidade ou no campo. Para 
fim de garantir o anonimato, os estudantes que moram na cidade foram identificados pelas letras A, B, C, D e E; e os que moram no campo foram identificados pelas letras F, G, H, I e J.

Também foram realizadas entrevistas com três professores da EJA da Escola Abraham Lincoln para conhecer as dificuldades do ponto de vista pedagógico. Foram entrevistados os professores das disciplinas de Língua Portuguesa, Geografia e Ciências. Serão identificados como docente A, B e C. Foram entrevistados o diretor e o coordenador pedagógico da Escola Municipal de Ensino Fundamental Abraham Lincoln que estão ligados diretamente à EJA.

Todas as entrevistas foram anotadas no caderno de campo. E todos os entrevistados assinaram o termo de consentimento livre e esclarecido.

\section{Resultados e Discussão}

De acordo com o resumo técnico do censo da educação básica do INEP (Brasil, 2020), em 2019 o número de matrículas da educação de jovens e adultos (EJA) no Brasil diminuiu 7,7\%\%, chegando a 3,3 milhões. Essa queda ocorreu de forma similar nas matrículas da EJA de nível fundamental e de nível médio, que apresentaram redução de 8,1\% e 7,1\%, respectivamente. Na EJA de nível fundamental, 65,8\% das matrículas estão na rede municipal, seguida pela rede estadual e pela rede privada, que apresentam $29,9 \%$ e $4,2 \%$, respectivamente. A EJA concentra, proporcionalmente, o maior número de matrículas na zona rural $(18,7 \%)$.

Segundo o estudo do INEP (BRASIL, 2020), o perfil dos estudantes da educação de jovens e adultos (EJA) é composto, predominantemente, por alunos com menos de 30 anos, que representam $62,2 \%$ das matrículas. Nessa mesma faixa etária, os alunos do sexo masculino são maioria, representando $57,1 \%$ das matrículas. Por outro lado, foi apresentado pelo INEP que as matrículas de estudantes acima de 30 anos são predominantemente compostas pelo sexo feminino, representando $58,6 \%$.

O resumo técnico também apresenta que, quanto à cor, percebe-se que os alunos identificados como pretos/pardos são predominantes na Educação de Jovens e Adultos (EJA) do ensino fundamental e médio, representando 75,8\% do EJA fundamental e $67,8 \%$ do EJA médio. Os alunos declarados como brancos representam $22,2 \%$ do EJA fundamental e $31 \%$ do EJA médio (BRASIL, 2020).

A Educação de Jovens e Adultos na Escola Municipal de ensino fundamental Abraham Lincoln tem público bem diferenciado por se tratar de um município predominantemente rural, dada a forte relação socioeconômica com a agricultura, e por se tratar de uma escola da cidade que atende aos estudantes camponeses. Nessa escola, a EJA iniciou no ano de 2003, e funcionava no período noturno, por disciplina em módulo.

\subsection{O quadro de abandono escolar na EJA da escola Abraham Lincoln}

A escola Abraham Lincoln é a maior instituição de ensino do município com cerca de dois mil alunos matriculados por ano, sendo que $70 \%$ são alunos de várias localidades rurais, chamadas de vicinais ou travessões, que diariamente se deslocam de suas residências, por meio do transporte escolar público ou particulares, para terem acesso às aulas.

É essa escola que tem o maior percentual de estudantes matriculados na EJA, e os dados coletados nos relatórios finais das turmas constatam expressivo abandono escolar desde a primeira turma ofertada em 2003, conforme pode ser observado na Tabela 1 pelos números de matrículas iniciais e finais e a quantidade de alunos que abandonaram seus estudos no período de 2003 a 2017, todos com a quantidade de alunos por sexo e o total geral (T). 
Tabela 1. Matriculados inicial e final, abandono de 2003 a 2017 no EJA, Escola Abraham Lincoln, Medicilândia, Pará.

\begin{tabular}{|c|c|c|c|c|c|c|c|c|c|}
\hline \multirow{2}{*}{$\stackrel{\bigcirc}{Z}$} & \multicolumn{3}{|c|}{ MATRICULA INICIAL } & \multicolumn{3}{|c|}{ ABANDONO } & \multicolumn{3}{|c|}{ MATRÍCULA FINAL } \\
\hline & M & $\mathbf{F}$ & $\mathbf{T}$ & $\mathbf{M}$ & $\mathbf{F}$ & $\mathbf{T}$ & $\mathbf{M}$ & $\mathbf{F}$ & $\mathbf{T}$ \\
\hline 2003 & 226 & 169 & 395 & 120 & 61 & 181 & 106 & 108 & 214 \\
\hline 2004 & 247 & 207 & 454 & 177 & 125 & 302 & 70 & 82 & 152 \\
\hline 2005 & 189 & 189 & 378 & 89 & 76 & 165 & 100 & 113 & 213 \\
\hline 2006 & 264 & 242 & 506 & 153 & 125 & 278 & 111 & 117 & 228 \\
\hline 2007 & 165 & 168 & 333 & 71 & 68 & 139 & 94 & 100 & 194 \\
\hline 2008 & 192 & 212 & 404 & 87 & 63 & 150 & 105 & 149 & 254 \\
\hline 2009 & 288 & 300 & 588 & 144 & 100 & 244 & 144 & 200 & 344 \\
\hline 2010 & 299 & 289 & 588 & 130 & 105 & 235 & 169 & 184 & 353 \\
\hline 2011 & 267 & 210 & 477 & 130 & 103 & 233 & 137 & 107 & 244 \\
\hline 2012 & 185 & 160 & 345 & 108 & 73 & 181 & 77 & 87 & 164 \\
\hline 2013 & 190 & 142 & 332 & 86 & 57 & 143 & 104 & 85 & 189 \\
\hline 2014 & 144 & 104 & 248 & 72 & 52 & 124 & 72 & 52 & 124 \\
\hline 2015 & 115 & 66 & 181 & 62 & 35 & 97 & 53 & 31 & 84 \\
\hline 2016 & 109 & 98 & 207 & 50 & 41 & 91 & 59 & 57 & 116 \\
\hline 2017 & 156 & 78 & 234 & 71 & 22 & 93 & 85 & 56 & 141 \\
\hline Total & 3036 & 2634 & 5670 & 1550 & 1106 & 2556 & 1486 & 1528 & 3014 \\
\hline
\end{tabular}

Legenda: M-masculino; F- feminino; T- total. Fonte: EMEFAL (2020).

Ao observar os dados da Tabela 1, nota-se que sempre houve um grande número de matrículas nessa modalidade de ensino. Em 2003 houve a matrícula inicial de 395 alunos, desses 226 eram do sexo masculino e ao final do ano, 191 alunos abandonaram seus estudos, sendo 120 do sexo masculino e 61 do sexo feminino.

A Tabela 1 evidencia a relevância do índice de abandono da EJA na escola, pois do total de 5670 matriculados de 2003 a 2017, 2696 estudantes desistiram dos estudos, ou seja, o abandono escolar atingiu o percentual médio de 47,5\%.

Na Tabela 2 estão os dados de quantidade de estudantes matriculados e desistentes, com o percentual de abandono, destacando em negrito os anos com índices de abandono igual ou maior que $50 \%$.

Tabela 2. Número de matriculados, desistentes, e percentual de abandono de 2003 a 2017.

\begin{tabular}{|c|c|c|c|c|c|c|c|c|c|c|c|c|c|c|c|}
\hline Ano & $\mathbf{2 0 0 3}$ & $\mathbf{2 0 0 4}$ & $\mathbf{2 0 0 5}$ & $\mathbf{2 0 0 6}$ & $\mathbf{2 0 0 7}$ & $\mathbf{2 0 0 8}$ & $\mathbf{2 0 0 9}$ & $\mathbf{2 0 1 0}$ & $\mathbf{2 0 1 1}$ & $\mathbf{2 0 1 2}$ & $\mathbf{2 0 1 3}$ & $\mathbf{2 0 1 4}$ & $\mathbf{2 0 1 5}$ & $\mathbf{2 0 1 6}$ & $\mathbf{2 0 1 7}$ \\
\hline $\begin{array}{c}\text { Total } \\
\text { matriculados }\end{array}$ & 395 & 454 & 378 & 506 & 333 & 404 & 588 & 588 & 477 & 345 & 332 & 248 & 181 & 207 & 234 \\
\hline $\begin{array}{c}\text { Total de } \\
\text { desistentes }\end{array}$ & 181 & 302 & 165 & 278 & 139 & 150 & 244 & 265 & 233 & 181 & 143 & 124 & 97 & 91 & 93 \\
\hline $\begin{array}{c}\text { Percentual } \\
\text { de abandono }\end{array}$ & 48,4 & $\mathbf{6 6 , 5}$ & 43,7 & $\mathbf{5 4 , 9}$ & 41,7 & 37,1 & 41,5 & 45,1 & 48,8 & $\mathbf{5 2 , 5}$ & 43,1 & $\mathbf{5 0 , 0}$ & $\mathbf{5 3 , 6}$ & 44,0 & 39,7 \\
\hline
\end{tabular}

Fonte: EMEFAL (2020).

Os da Tabela 2 indicam que o ano em que ocorreu o menor número de alunos que abandonaram seus estudos foi em 2016, com noventa e um alunos desistentes, do qual 50 era do sexo masculino e 41 do feminino, representando $44 \%$ do total. O maior índice de abandono foi em 2004, com 66,5\%, representado por trezentos e dois alunos desistentes (Tabela 2). Os maiores percentuais de abandono ao longo dos anos foram nos anos de 2004, 2006, 2012, 2014 e 2015.

Nos anos de maior índice de abandono escolar na EJA prevalece uma porcentagem maior de desistências de pessoas do sexo masculino (Figura 1), sendo que em 2003 foi de quase o dobro em relação ao sexo feminino, e em 2017, a diferença 
fica maior, sendo mais do que o triplo. No período em análise, 58\% das desistências são de estudantes do sexo masculino. Assim, se torna relevante identificar o que tem levado ao abandono em cada gênero.

Figura 1. Abandono escolar entre os sexos feminino e masculino de 2003 a 2017, na Escola Abraham Lincoln, Medicilândia, Pará.

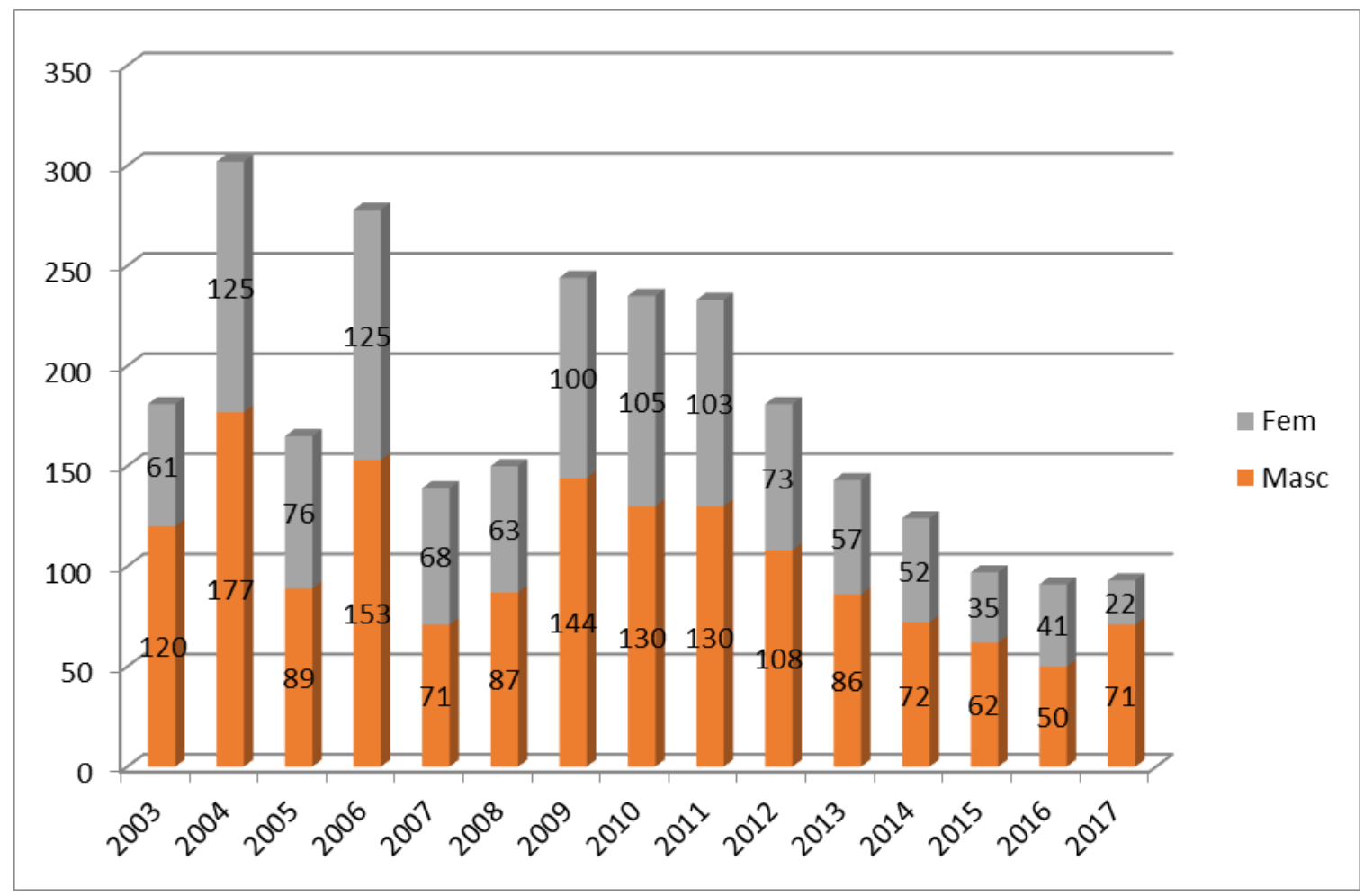

Fonte: EMEFAL (2020).

De acordo com Santos e Albuquerque (2019), em nível nacional, nos últimos anos ocorreu uma redução na taxa de abandono no ensino fundamental e médio. Em 2007, os anos finais do fundamental apresentavam uma taxa de abandono na faixa de 6,7\%, e em 2017 chegou a 2,8\%, sendo que as taxas mais elevadas estão nos anos finais do ensino fundamental. No entanto, quando se vê a realidade da EJA, retratada na principal escola de Medicilândia, a taxa de abandono está extremamente acima da média nacional. Apesar disso, não foram constatadas medidas específicas para alterar o quadro no município.

\subsection{Motivos que levaram ao abandono escolar na EJA}

Uma questão relevante para pensar uma educação humanizada é saber quem são os sujeitos da EJA. Silva (2017) e Arroyo (2017) enfatizam que enquanto educadores e gestores precisamos responder: quem são esses adolescentes, jovens e adultos da EJA? Até que ponto são reconhecidos como sujeitos coletivos de direitos? Quais as expectativas desses sujeitos?

No quadro 1, as informações sobre idade, gênero, situação familiar e de trabalho oferecem algumas pistas quanto a quem são esses sujeitos que moram e trabalham na cidade e abandonaram seus estudos, e também os motivos que levaram à desistência. Dos dez estudantes desistentes entrevistados, cinco moram na cidade, sendo três do sexo masculino e dois do sexo feminino, com idade entre 26 e 40 anos. Os que moram nas localidades rurais, foram três agricultores e duas agricultoras, com idade entre 21 e 54 anos. 
Quadro 1. Motivos que levaram ao abandono escolar de alunos da área urbana.

\begin{tabular}{|l|l|l|l|l|l|}
\hline Aluno & Idade & Sexo & Estado civil & Tipo de trabalho & $\begin{array}{l}\text { Motivos que levaram a } \\
\text { abandonar seus estudos }\end{array}$ \\
\hline A & 26 & F & União estável & comércio & $\begin{array}{l}\text { Trabalho/problemas } \\
\text { familiares }\end{array}$ \\
\hline B & 28 & M & Solteiro & Diárias esporádicas & $\begin{array}{l}\text { Falta de interesse; } \\
\text { desistências recorrentes }\end{array}$ \\
\hline C & 28 & M & União estável & Comércio/ açougue & $\begin{array}{l}\text { Trabalho; desistências } \\
\text { recorrentes }\end{array}$ \\
\hline D & 40 & F & Casada & $\begin{array}{l}\text { Trabalho doméstico } \\
\text { familiar; doméstica para } \\
\text { terceiros (diarista). }\end{array}$ & Problemas familiares \\
\hline E & 38 & M & Casado & comércio & Trabalho \\
\hline
\end{tabular}

Fonte: Pesquisa de campo (2020).

A aluna A tem 26 anos e trabalha no comércio local. Matriculou-se para cursar a $4^{\mathrm{a}}$ Etapa da EJA no ano de 2015, mas cursou apenas a primeira disciplina do primeiro semestre e acabou desistindo por não conseguir conciliar trabalho e estudo. Passou um ano sem frequentar a escola e no ano de 2017 retomou seus estudos, mas, novamente desistiu no primeiro mês, dessa vez foi por ter se casado e o esposo não permitir que continuasse a estudar.

O aluno B tem 28 anos de idade e não tem trabalho fixo, sobrevive de serviços esporádicos como diarista. Conforme afirmado por ele tem uma ficha bem longa por desistências, pois se matriculou nos anos de 2014, 2016 e 2017, e desistiu em todos. No ano de 2014 cursou apenas a primeira disciplina e desistiu, segundo ele, por falta de interesse; em 2016 cursou apenas 02 disciplinas e devido indisciplina sempre estava com advertências e acabou desistindo novamente. Em 2017, voltou a estudar diante da assinatura de um termo de compromisso, mas só estudou o primeiro semestre.

$\mathrm{O}$ aluno $\mathrm{C}$ tem 28 anos de idade, trabalha em um açougue. $\mathrm{O}$ mesmo tem um histórico de três anos de desistências, sendo no ano de 2013, 2014 e 2016. No ano de 2013 cursou apenas as duas primeiras disciplinas e dessas reprovou em uma, e devido a isso já desistiu no início, já que não progrediria de ano em seus estudos. No próximo ano realizou novamente sua matrícula, cursou apenas a primeira disciplina e desistiu por ter conseguido um emprego e não conseguir conciliar os dois. Em 2016, para conseguir efetivar sua matrícula novamente teve que assinar um termo de compromisso, porém, também não concluiu o ano letivo por chegar muito atrasado devido ao trabalho.

A aluna D tem 40 anos de idade, trabalha como diarista de atividade doméstica, a mesma matriculou-se durante dois anos a fim de concluir seu ensino fundamental, porém, não obteve sucesso. No ano de 2014 matriculou-se e cursou três disciplinas com médias boas, mas, desistiu devido ser mãe e seu esposo não aceitava o fato dela estudar. Passaram dois anos, e segundo ela, com muita luta conseguiu convencer o esposo a deixá-la estudar, mas sua filha engravidou, teve complicações e precisou de seus cuidados, e novamente abandonou seus estudos.

$\mathrm{O}$ aluno E tem 38 anos, trabalha no comércio local. O mesmo relatou que teve oportunidade de estudar quando era criança no estado do Maranhão, porém, como sua documentação escolar referente aos dois primeiros anos de estudo foi extraviada. Em 2014 soube por amigos que a escola estava ofertando um tipo de teste para as pessoas que tinham vontade de estudar, mas que por alguma razão não conseguiram. Assim, o mesmo procurou a escola e realizou o teste classificatório em nível de $1^{\mathrm{a}}$ Etapa e foi aprovado, efetivando sua matrícula na $2^{\mathrm{a}}$ etapa. O mesmo cursou parte do primeiro semestre e desistiu pelo fato de não ser liberado do trabalho no horário certo e por isso chegava todos os dias atrasados, não acompanhando as explicações do conteúdo pelo professor. Diante dessa situação decidiu não prosseguir seus estudos.

Pode-se notar que dentre os principais motivos estão as condições de trabalho que levam à incompatibilidade com os estudos, por chegarem atrasados, não acompanharem o ritmo das aulas, ter dificuldade de compreensão de conteúdos, 
pressionados pelo cansaço e sono decorrentes de trabalhos penosos. Foi mencionado pelas mulheres entrevistadas o termo "problemas familiares" que pode ser a insatisfação ou mesmo impedimento feito pelo marido, necessidade de cuidar dos filhos ou outras no âmbito familiar. Um terceiro motivo foi a falta de interesse, que não foi o suficientemente abordado pelos entrevistados, já que foi apontado como algo desatrelado das condições sociais e econômicas que se encontravam ou das expectativas que os mesmos tem ou tinham da escola. Temos três elementos importantes para análise dos motivos do abandono escolar: as condições enquanto trabalhador, a questão de gênero e a expectativa em relação à escola. Apesar dos entrevistados não terem mencionado as condições de ensino e a qualidade da aprendizagem, esse elemento não pode ser desatrelado do que chamaram de falta de interesse e não conseguirem acompanhar o conteúdo por chegarem atrasado.

No Quadro 2 estão sistematizados os dados gerados nas entrevistas com estudantes que moram na área rural.

Quadro 2. Motivos que levaram ao abandono escolar de alunos que moram na área rural.

\begin{tabular}{|l|l|l|l|l|l|}
\hline Nome & $\begin{array}{l}\text { Idade } \\
\text { (anos) }\end{array}$ & Sexo & Estado Civil & Tipo de trabalho & $\begin{array}{l}\text { Motivos Levaram } \\
\text { abandonar seus estudos }\end{array}$ \\
\hline F & 25 & M & Solteiro & Na roça/no cacau & $\begin{array}{l}\text { Falta de transporte público } \\
\text { regular }\end{array}$ \\
\hline G & 21 & F & União estável & $\begin{array}{l}\text { No cacau e em casa de } \\
\text { família }\end{array}$ & $\begin{array}{l}\text { Gravidez/ transporte escolar } \\
\text { não regular }\end{array}$ \\
\hline H & 25 & M & União estável & Na roça/no cacau & $\begin{array}{l}\text { Transporte } \\
\text { Problemas de saúde com a } \\
\text { esposa }\end{array}$ \\
\hline I & 54 & M & Casado & Na roça/no cacau & Trabalho \\
\hline J & 37 & F & Casada & Na roça/no cacau & Atividades de casa \\
\hline
\end{tabular}

Fonte: Pesquisa de campo (2020).

O Aluno F tem 25 anos de idade, reside a cerca de 20 quilômetros da cidade, trabalha na agricultura especificamente com o cultivo de cacau. O mesmo matriculou-se no ano de 2013 para cursar a $4^{\text {a }}$ etapa da Educação de Jovens e Adultos, estudou até metade do primeiro semestre e por falta de transporte não pôde prosseguir. O mesmo relata que mesmo trabalhando o dia inteiro no cacau e à noite estar cansado, vinha para a escola, e considera que não concluiu devido à falta de compromisso da gestão municipal para garantir transporte regular para os estudantes. Ainda tentou novamente, matriculandose no ano de 2019, mas desistiu novamente por falta de transporte.

A aluna $\mathrm{G}$ tem 21 anos de idade, trabalha em sua propriedade com a lavoura de cacau e nas atividades domésticas de sua casa, e parte do tempo trabalha como diarista em atividades domésticas nas casas de terceiros. A mesma matriculou-se para cursar a $4^{\text {a }}$ etapa no ano de 2017, estudou até o meio do ano, mas não prosseguiu os estudos devido engravidar e o transporte escolar público não ser regular.

O Aluno $\mathrm{H}$ reside a oito quilômetros da cidade, trabalha na lavoura de cacau. O mesmo matriculou-se nos anos de 2017, 2018 e 2019, porém, em todos foi desistente. No primeiro ano cursou parte da disciplina de Matemática, e por falta de transporte foi obrigado a desistir e no ano seguinte estudou até o mês de setembro e desistiu pelo mesmo motivo. Em 2019 efetuou sua matricula novamente, mas cursou apenas o primeiro bimestre e parte do segundo, e devido ter casado e sua esposa engravidar teve que desistir por se tratar de uma gravidez de risco.

O aluno I tem 54 anos de idade e reside na área rural do município; matriculou-se no ano de 2014 para cursar a $3^{\mathrm{a}}$ etapa, cursou apenas as três primeiras disciplinas e teve que parar no período de colheita da safra de cacau dado ao tempo e esforço que precisava dedicar à lavoura. Em 2017, matriculou-se novamente, estudou até parte do terceiro bimestre, e resolveu abandonar por perder muitas aulas devido ao trabalho na roça.

A aluna $\mathbf{J}$ tem 37 anos de idade, também trabalha com a lavoura de cacau. A mesma matriculou-se no ano de 2017 para cursar a $4^{\mathrm{a}}$ etapa e por ser dona de casa e o esposo trabalhar de meeiro em roça de cacau, foi obrigada a desistir para 
auxiliar o esposo a garantir a logística para os trabalhadores contratados pelo companheiro. A mesma disse que o período de safra é complicado para quem mora na roça, e defendeu que deveria ter um ensino diferenciado para essas pessoas que moram na área rural e precisam trabalhar.

Os desistentes da área rural, além de não conseguirem conciliar com a jornada e a penosidade do trabalho, evidenciaram a falta de transporte público regular como um fator para o abandono escolar. A falta de transporte também foi importante por dependerem das condições do veículo e das estradas, levando a atrasos no horário ou mesmo na indisponibilidade do serviço.

Entre os homens, o trabalho predominou como a causa principal do abandono escolar.

Conciliar estudo e trabalho não é uma tarefa fácil, exige esforço individual e coletivo, pois para que isso tenha êxito necessita-se de uma ação em conjunto, tendo em vista que essas pessoas trabalham até mais de oito horas por dia, e ao chegarem à noite no seu momento de descanso vão para a escola para ter uma formação, almejando mais conhecimento e melhores condições econômicas para si e sua família. Sobre essa relação entre estudo e trabalho Oliveira, Barreto e Litka (2011, p. 09) dizem o seguinte: “As dificuldades resultantes do conflito entre o mundo do trabalho e a escola, aliadas à dificuldade de aprendizagem, contribuem para desenvolver uma sensação de impotência, falta de competência e desmotivação frente aos estudos [...]".

Apesar de ter seu direito garantido na Lei de Diretrizes e Bases da Educação Nacional (Brasil, 1996), em seu artigo $23^{\circ}$ e $\S 2^{\circ}$ que orienta que o calendário escolar deverá adequar-se às peculiaridades locais, inclusive climáticas e econômicas, o sistema de ensino não tem se adequado à essa diretriz. Isso leva ao município a não estabelecer calendário ou currículo diferenciados para o campo ou para a realidade dos trabalhadores, contrariando o estabelecido no artigo $28^{\circ}$ :

Na oferta de educação básica para a população rural, os sistemas de ensino promoverão as adaptações necessárias à sua adequação às peculiaridades da vida rural e de cada região, especialmente:

I - conteúdos curriculares e metodologias apropriadas às reais necessidades e interesses dos alunos da zona rural;

II - organização escolar própria, incluindo adequação do calendário escolar às fases do ciclo agrícola e às condições climáticas;

III - adequação à natureza do trabalho na zona rural.

A falta da oferta de alternativas agrega um índice de abandono escolar não só na modalidade de ensino da EJA, mas em todo o sistema de ensino regular, pelo fato de que nessa escola a maioria de seus alunos é da área rural e, na época de colheita na safra do cacau, muitos filhos deixam de vir para escola para ajudarem seus pais. Assim, se tem convivido com esse quadro de abandono e subsequente evasão escolar, que envolvem questões sociais, econômicas, de políticas públicas e ainda se tem problemas ligados ao currículo e práticas pedagógicas ainda não diferenciadas conforme o público de trabalhadores e trabalhadoras que buscam no EJA a garantia do direito à educação (Arroyo, 2017). Diante desse quadro, a política educacional do município deveria passar por mudanças, como no âmbito pedagógico, como apontado por Cardoso \& Hage (2017, p. 183): "Uma delas, voltada ao campo pedagógico, trata-se da formação continuada dos docentes da EJA; do currículo pensado na interculturalidade relacionada às práticas sociais vivenciadas no cotidiano social e escolar, identificando o modo de ser, de viver cultural desses sujeitos que trazem para dentro da escola suas experiências de vida, histórias, afetividades, cultura, religiosidade etc.”. Ou seja, reconhecer e colocar na prática a imbricação entre o social e o pedagógico na política educacional.

\subsection{Dificuldades pedagógicas na EJA: ponto de vista dos docentes}

No quadro 3 estão apresentadas algumas características dos docentes entrevistados. Pelas informações, os mesmos atuam de 8 a 21 anos como educadores e de 4 a 5 anos com o público da EJA. Tem um professor concursado que complementa a carga horária nas turmas da EJA e dois contratados temporariamente com dedicação exclusiva para a EJA. 
Quadro 3. Informações dadas pelos docentes do EJA da Escola Abraham Lincoln.

\begin{tabular}{|l|l|l|l|l|l|l|}
\hline Docente & Idade & Formação de & $\begin{array}{l}\text { Área } \\
\text { atuação } \\
\text { docente }\end{array}$ & $\begin{array}{l}\text { Anos de } \\
\text { profissão } \\
\text { EJA na }\end{array}$ & $\begin{array}{l}\text { Efetivo ou } \\
\text { contratado }\end{array}$ \\
\hline A & 34 & $\begin{array}{l}\text { Cursando Licenciatura } \\
\text { em Educação do Campo } \\
- \text { UFPA / Pedagogia }\end{array}$ & 8 & 4 & Contratada \\
\hline B & 28 & $\begin{array}{l}\text { Licenciatura Plena em } \\
\text { Letras - Língua } \\
\text { Portuguesa - UFPA }\end{array}$ & $\begin{array}{l}\text { Língua } \\
\text { Portuguesa }\end{array}$ & 8 & 5 & Contratado \\
\hline C & 44 & $\begin{array}{l}\text { Licenciatura em } \\
\text { Geografia, Geografia } \\
\text { especialista em Meio } \\
\text { ambiente e química }\end{array}$ & 21 & 5 & Efetivo \\
\hline
\end{tabular}

Fonte: Pesquisa de campo (2020).

Os professores têm dificuldade para estabelecerem uma linguagem diferenciada para se comunicar com os sujeitos da EJA, pois a maioria trabalhava com crianças de até 14 anos, o que leva a alguns dizerem que não se identificam ou não se sentem totalmente capacitados para lidar com jovens e adultos. Como afirma Rossini (2001), “os professores nem sempre estão preparados para atuarem na modalidade da EJA, pois, pelo fato de já atuarem na educação de crianças, muitas vezes utilizam métodos que tendem a infantilizar os adultos, desconsiderando as peculiaridades e características próprias".

Dentre os professores entrevistados, dois deles se identificam na docência com jovens e adultos. A docente A diz que se identifica com esse público porque são pessoas que não tiveram oportunidades de estudar no ensino regular. O docente B se identifica porque diz ver que muitas pessoas estão em busca de oportunidades e sente o trabalho dele fluir mais do que nas demais turmas, pois, para ele esses alunos admiram e respeitam mais o professor. Já a docente C diz não se identificar com esse público, e justifica que é porque a realidade da sala de aula não condiz com a proposta feita pela modalidade de ensino, uma vez que teoricamente a Educação de Jovens e Adultos necessitaria de diretrizes pedagógicas diferenciadas e ofertado apenas para as pessoas que por algum motivo não puderam estudar, conforme o documento nacional de base (Brasil, 2009; Soares, 2002; Pará, 2009).

Na visão da docente: "se verifica no dia a dia que tem adolescentes de 15 anos sendo matriculados na EJA, sem nenhuma justificativa plausível que inviabilize sua matrícula no ensino regular”. Para a docente existe uma distorção na perspectiva da EJA, e que por estar diversificando ainda mais o perfil dos sujeitos, tem dificultado o processo de ensino.

Ao analisar dados estatísticos dos relatórios finais da escola desde o ano de 2003, pode se perceber que até o ano de 2010 o público da EJA era de pessoas adultas. Porém, a partir desse ano de 2010 começou-se aceitar matrículas de muitos adolescentes. Isso levou a alterações no planejamento ou metodologias adotadas?

A docente A relatou que a matrícula desses adolescentes trouxe problemas para a escola, pois, muitos deles não querem estudar e acabam atrapalhando a vida estudantil dos mais velhos, e com isso tem que ter um pouco mais de trabalho para planejar a aula, e muitas vezes durante a aula tem que ficar chamando a atenção desses adolescentes.

O docente $\mathrm{B}$ também concordou que a diminuição da faixa etária traz muitos problemas para a escola, e que com isso cresceram os números relacionados à desistência e problemas em sala de aula, inclusive brigas entre alunos e dificuldades diversas no processo de ensino-aprendizagem, causando desconforto nos mais velhos e precisando fazer sempre um trabalho educativo e incentivador diante das dificuldades. E que, além disso, constantemente, os professores precisam fazer relação dos ausentes na tentativa de resgatar alguns da desistência. 
Para a docente C, o abandono escolar é um dos maiores problemas enfrentados, pois com a matrícula desses alunos na EJA, que é ofertado somente no período noturno "os adolescentes vêm para a escola apenas no intuito de passear, e isso acaba atrapalhando quem realmente quer estudar". Essa fala mostra a dificuldade dos professores com essa diversidade e em como enxergar a escola como também esse ambiente de encontro com o outro, e que tenham instrumentos pedagógicos para reverter a situação de descompromisso com o aprendizado.

Essa diminuição da faixa etária deveria gerar ações específicas da Secretaria Municipal de Educação para aportar condições e formação para os docentes, dada à "juvenilização da EJA” e expansão da diversidade de sujeitos, que poderia ser visto como algo positivo em termos pedagógicos e dos aprendizados. Stoll, Bierhalz, Alves, Chaves \& Castro (2020) apontaram em seu estudo o aumento de jovens, mas ao contrário de ver como problema, os autores se dedicam a analisar o perfil, percepções e expectativas desses sujeitos na EJA para se repensar estratégias didático-pedagógicas.

Como já especificado no documento das diretrizes:

EJA é espaço de tensão e aprendizado em diferentes ambientes de vivências, que contribuem para a formação de jovens e de adultos como sujeitos da história. Negros, brancos, indígenas, amarelos, mestiços; mulheres, homens; jovens, adultos, idosos; quilombolas, pantaneiros, ribeirinhos, pescadores, agricultores; trabalhadores ou desempregados - de diferentes classes sociais; origem urbana ou rural; vivendo em metrópole, cidade pequena ou campo; livre ou privado de liberdade por estar em conflito com a lei; pessoas com necessidades educacionais especiais - todas elas instituem distintas formas de ser brasileiro, que precisam incidir no planejamento e execução de diferentes propostas e encaminhamentos para a EJA (Pará, 2009, p.2).

Como exposto pelo docente B, o mesmo cobra maior efetividade do poder público, tendo em vista essas peculiaridades dos sujeitos, devendo: “considerar as origens sociais, faixa etária, estruturar o ambiente adaptando-o para oportunizar aos docentes a prática de metodologias ativas e apoio pedagógico".

Para se trabalhar a EJA com metodologias diferenciadas são necessários alguns recursos didáticos pedagógicos para que o mesmo ocorra. Diante disto, foi perguntado aos docentes se suas aulas conseguem atingir seus objetivos, e se os mesmos dispõem de recursos pedagógicos para execução do trabalho.

A docente A disse que seria ótimo se conseguisse atingir todos os objetivos, mas que isso não é possível, já que não dispõe de recursos, e que trabalha com o que pode, e às vezes utiliza seu próprio equipamento, como o notebook, para melhoria da aula, faltando materiais básicos como pincel e apagador. A docente $\mathrm{C}$ disse que alcançar os objetivos do ensino depende da turma, dia e horário, pois quando as aulas são nos primeiros horários há baixa frequência e acompanhamento das explicações.

O docente B explica que há vários fatores a serem considerados para atingir os objetivos pedagógicos almejados, como a frequência e o atraso de muitos que passaram o dia trabalhando e chegam cansados na escola, o que se dá com maior intensidade na sexta feira. Também expõe que por diversas vezes os recursos multimídias, caixa de som e os espaços da escola não foram disponibilizados para as atividades planejadas. Em relação aos livros didáticos, foi destacado que não existem livros específicos para os alunos e professores da EJA. O material didático é pesquisado e elaborado pelo docente.

Como exposto anteriormente, as estratégias didático-pedagógicas precisam estar em conformidade com a diversidade de sujeitos, suas potencialidades e objetivos, repensando seu caráter para que sejam menos conteudista e que gere emancipação e autonomia (Freire, 1996), conforme consta no Documento Base Nacional:

As estratégias político-didático-pedagógicas na EJA fundamentam-se em como viabilizar a superação de outros processos ainda marcados pela organização social da instituição escola, hierarquizada em um sistema verticalizado, em uma lógica disciplinar, com saberes e conhecimentos tomados como "conteúdos" fragmentados e estáticos, distantes da realidade e acríticos, que dificultam a legitimação dos saberes historicamente construídos por homens e mulheres (Brasil, 2009, p. 33). 
Dentre as sugestões para diminuir o índice de abandono escolar, a docente A considera que não é apropriado matricular adolescentes junto com adultos trabalhadores, por considerar que os adolescentes atrapalham por terem menos interesse pelo aprendizado: “a maioria deles só atrapalha a aula e o professor tem que ficar chamando a atenção o tempo todo, e isso faz com que desistam quem realmente quer estudar".

Para o docente B, faz-se necessário um trabalho em conjunto, enfatizando que a Secretaria Municipal de Educação poderia promover políticas para atender essa demanda com projetos que despertassem mais interesse aos alunos através de parcerias com outras instituições para a oferta de cursos de capacitação, inserir no currículo algo voltado ao aperfeiçoamento profissional, assim como propôs criar competições, gincanas, e investir em formação continuada para os profissionais, com o propósito de juntamente com o corpo pedagógico, discente e administrativo da instituição repensarem os caminhos dessa modalidade, e também sugere que os gestores e os professores façam constantes avaliações, inclusive das práticas educativas e metodológicas.

A sugestão da docente $C$ foi de transformar o curso de Educação de Jovens e Adultos em outra modalidade, como de cursos profissionalizantes, e também proporcionar metodologias diferenciadas.

Essas sugestões feitas pelos docentes denotam uma crise de identidade que passa a EJA no município, em que a educação focada no mercado via capacitação profissional é vista como solução. Há de se indagar se os professores conhecem as expectativas e os projetos pessoais e coletivos dos estudantes. Há de perguntar quais os objetivos da educação escolar para esses sujeitos. Outro ponto de questionamento é que o ser camponês não é considerado no projeto pedagógico da escola, pois apenas nesse aspecto já se deveria balançar a matriz curricular da EJA, introduzindo novas formas de fazer e de conceber a educação.

Diante de um cenário de tantas desistências nesta modalidade de ensino nesta instituição, os docentes A e C disseram que atribuem esse problema à falta de compromisso por parte dos alunos mais jovens e por não estarem dispostos a estudar. Segundo esses docentes, os estudantes vão para escola para bater papo e isso acaba atrapalhando os que querem estudar. Ou seja, está faltando interesse para estudar e também um olhar docente mais profundo sobre essa juventude e como a escola pode proporcionar esse espaço de convivência, de socialização, e também de construção de conhecimentos que envolvam a todos.

O docente $\mathrm{B}$ disse que são vários fatores que acarretam o problema, pois a maioria dos estudantes é de pessoas de baixa renda que precisam trabalhar para sustentar a família, e que mesmo os mais jovens são pessoas que enfrentam dificuldades socioeconômicos. Tratando em especial dessas questões, diz que muitos alunos antes de desistirem relatam que trabalham mais de oito horas por dia sem tempo para almoço e por vezes vem para escola sem alimentar-se, outros não frequentam as aulas por períodos longos para trabalharem nas lavouras e quando retornam encontram dificuldades de acompanhar as disciplinas. O mesmo diz que nem todos os docentes estão abertos a essas questões e também não existem regras regimentais acadêmicas para essas situações. E que alguns também desistem porque são advertidos por indisciplina e acabam sofrendo restrições, além de problemas familiares, conjugais, já mencionados anteriormente.

A Educação de Jovens e Adultos ao ser repensada em sua estrutura pedagógica, esteja coerente para o enfrentamento dos inúmeros problemas apontados. Esse redirecionamento pode ser dado a partir da pista apresentada pelo professor B:

"São pessoas com dilemas de vida tão ricos, mesmo os mais jovens, trazem aprendizados que se aproveitados podem fazer fluir o trabalho. Vi a satisfação dos mais velhos em contar suas memórias e os mais jovens relacionarem com suas atitudes e seus mundos. Vi pessoas que mesmo diante de todas as dificuldades conseguiram continuar seus estudos e concluírem o ensino médio e mantiveram o carinho e o respeito por seus professores. Isso é minha motivação!" (Docente B). 
O estudo de Santos e Albuquerque concluíram sobre as características do corpo docente e como essas podem influenciar para diminuir o abandono escolar. Segundo os autores, o planejamento cuidadoso e um quadro docente perene são essenciais para garantir a permanência dos estudantes:

[...] maior regularidade do corpo docente e maior percentual de professores com ensino superior são características dos estabelecimentos com menores taxas de abandono, especificamente no ensino médio. A alta rotatividade de professores nas escolas pode afetar o estabelecimento de vínculos com a instituição e com os estudantes, pois um docente que permanece pouco tempo na escola tem menos condições de identificar situações específicas dos estudantes e da comunidade atendida, de dar continuidade a planejamentos ou de contribuir na resolução de eventuais problemas pelos quais a escola possa estar passando (Santos \& Albuquerque, 2019, p. 26-27).

Xavier, Seruffo \& Pires (2020) destacaram a falta de afinidade dos profissionais pela formação de jovens e adultos, em que $61,55 \%$ alegaram complementar a carga horária na EJA e outros 15,38\% indicaram afinidade.

\subsection{Dificuldades pedagógicas: ponto de vista da direção e coordenação da EJA na Escola Abraham Lincoln}

Para se ter uma visão de como é o funcionamento e gestão da EJA nesta instituição de ensino, foram realizadas entrevistas também com a coordenadora e o vice-diretor que trabalha diretamente com esse público (Quadro 4), sendo que os mesmos estão a 20 e 30 anos como profissionais da educação.

Quadro 4. Dadas pelo vice-diretor e coordenador pedagógico do EJA da Escola Abraham Lincoln.

\begin{tabular}{|l|l|l|l|l|l|}
\hline Gestor & $\begin{array}{l}\text { Idade } \\
\text { (anos) }\end{array}$ & \multicolumn{1}{|c|}{ Formação } & \multicolumn{1}{|c|}{$\begin{array}{c}\text { Área de } \\
\text { atuação }\end{array}$} & $\begin{array}{c}\text { Anos } \\
\text { de } \\
\text { profissão }\end{array}$ & \\
\hline A & 44 & $\begin{array}{l}\text { Ciências Humanas e } \\
\text { Sociais. } \\
- \text { Especialização em Gestão } \\
\text { Escolar e Coordenação } \\
\text { Pedagógica }\end{array}$ & Vice- diretor & 20 & $\begin{array}{l}* \text { 04 anos na Coordenação } \\
\text { Pedagógica } \\
* \text { 02 anos na Direção }\end{array}$ \\
\hline B & 49 & $\begin{array}{l}\text { Pedagogia } \\
\text { Pós Graduação em } \\
\text { Psicopedagogia }\end{array}$ & Coordenadora & 30 & $\begin{array}{l}\text { Há 10 anos na Coordenação } \\
\text { pedagógica, mas diretamente com } \\
\text { a EJA, há 02 anos. }\end{array}$ \\
\hline
\end{tabular}

Fonte: Pesquisa de campo (2020).

Do ponto de vista dos gestores, as dificuldades para se trabalhar com a Educação de Jovens e Adultos são: o longo período que os estudantes ficaram foram da escola, a falta de suporte didático adaptado para a modalidade, a falta de formação específica para os professores atuarem na EJA e a grande evasão devido ao cansaço e muitas vezes por falta de estratégias pedagógicas para os estudantes de maior faixa etária. O fato de a maioria dos alunos residir na área rural explica a maior ausência nas aulas no período do inverno e no tempo das colheitas, o que compromete muito o aprendizado. Outra dificuldade apontada é menor importância dada pelos gestores para a EJA em comparação com as demais turmas.

A respeito de materiais pedagógicos, os gestores confirmaram que não existem livros didáticos e suporte tecnológico para dinamizar as aulas. E explicam que com a falta de livros didáticos que atendam às especificidades da EJA, os professores fazem adaptações, onde buscam os conteúdos em livros variados do ensino fundamental, além da pesquisa em internet para montar seus materiais.

Outro ponto diretamente relacionado aos problemas pedagógicos identificados envolve a lotação dos docentes nas turmas. Os mesmos são lotados em suas respectivas disciplinas no ensino regular e complementam a carga horária na EJA, não tendo o tempo adequado e a dedicação exclusiva para o planejamento e o trabalho docente com as turmas dessa modalidade. Ou seja, não existe um quadro permanente com dedicação exclusiva para a EJA. 
Para os entrevistados, dentre os pontos que influenciam no abandono escolar estão a faixa etária elevada e a diferença de idade dos alunos em uma única sala de aula. Segundo os mesmos, muitos alunos já chegam cansados do trabalho e apesar da vontade de estudar, acabam desistindo, e "outros procuram a escola apenas como um lugar de fazer amigos e se divertirem". Outro fator é a falta de um ensino diferenciado que se aproxime da realidade do aluno, a falta de incentivo material e humano, pois, reconhecem que os estudantes trazem muitos conhecimentos e experiências que não são valorizados. Neste sentido, pensam que para a modalidade ficar mais atrativa devem aproveitar esses saberes e contextualizar com conhecimentos científicos, assim, esses alunos se sentirão mais motivados, e poderem ser de fato sujeitos e se notarem no processo de construção dos conhecimentos.

Arroyo (2018) reforça que a reconfiguração da EJA será alcançada a partir do reconhecimento da especificidade dos jovens e adultos com suas trajetórias desses tempos de vida, juventude e vida adulta e da especificidade dos sujeitos concretos históricos que vivenciam esses tempos, que o ponto de partida para essa reconfiguração deverá ser primeiramente saber quem são esses jovens e adultos.

Por outro lado, também são necessários analisar a relação entre fatores externos e internos que influenciam no abandono escolar, como especifica Santos e Albuquerque (2019, p. 27), que reconhecem que o abandono se relaciona: “a um conjunto de fatores que variam de acordo com o contexto social, circunstâncias individuais, familiares. Ao mesmo tempo, fatores relativos à qualidade física e aos processos nos quais a escolarização ocorre [...]”. Necessitando conhecer melhor o processo para poder agir e assegurar a redução e a não reprodução do mesmo.

\section{Considerações Finais}

Levando-se em consideração todos os elementos mencionados que causam o abandono escolar, primeiramente foram destacadas as limitações impostas pelo mundo do trabalho, seja urbano ou do campo, em choque com as práticas pedagógicas e o calendário escolar adotado. Apesar dos gestores e docentes reconhecerem as questões sociais envolvidas, não se tem instrumentos educacionais claros e efetivos para lidar com o problema. Em seguida, a falta de garantia do transporte, principalmente para quem depende do transporte escolar público, e os problemas familiares, que são mais incisivos no abandono escolar de mulheres. Na perspectiva dos docentes e gestores, foram enfatizados o perfil dos estudantes com a presença de pessoas cada vez mais jovens e a falta de aporte pedagógico e de infraestrutura.

Fica evidente que o sistema adotado carece da construção de um projeto coerente e atualizado para a EJA, adotando currículos escolares diferenciados e projetos didáticos que contemplem a diversidade dos sujeitos e considerem as expectativas dos mesmos. Para isso, a retomada da perspectiva emancipatória da EJA e dos princípios da educação do campo levariam a novos rumos, e para orientarem processos de avaliação e de planejamento educacionais condizentes com as especificidades e necessidades camponesas e de suas escolas. Em termos de perspectivas de pesquisa, o aprofundamento da discussão sobre as políticas educacionais deve ser priorizado no sentido de construir novos rumos para a EJA na região.

\section{Referências}

Arroyo, M. G.; Caldart, R. S.; Molina, M. C. (2011). Por uma educação do campo. Petrópolis: Vozes.

Arroyo, M. (2017). Passageiros da noite: do trabalho para a EJA- itinerários pelo direito a uma vida justa. Petrópolis: Vozes.

Arroyo, M. (2018). Educação de Jovens e Adultos: um campo de direitos e de responsabilidade pública. In: Soares, L.; Giovanetti, M. A.; Gomes, N. L. (Org.). Diálogos na Educação de Jovens e Adultos. Belo Horizonte: Autêntica, p.19-50.

Brasil. (2000). Resolução de $n^{o}$ 01, de 05 de julho de 2000, do Conselho Nacional de educação (CNE), Diretrizes Curriculares Nacionais.

Brasil. Ministério da Educação. Secretaria de Educação Continuada, Alfabetização e Diversidade. (2009). Documento Nacional. Preparatório à VI Conferência Internacional de Educação de Adultos (VI CONFINTEA) / Ministério da Educação (MEC). - Brasília: MEC; Goiânia: FUNAPE/UFG. 
Research, Society and Development, v. 11, n. 3, e6911326365, 2022

(CC BY 4.0) | ISSN 2525-3409 | DOI: http://dx.doi.org/10.33448/rsd-v11i3.26365

Brasil. (2020). Instituto Nacional de Estudos e Pesquisas Educacionais Anísio Teixeira (Inep). Censo da Educação Básica 2019: resumo Técnico. Brasília.

Brasil. Lei n. 9.394, de 20 de dezembro de 1996. Estabelece as Diretrizes e Bases da Educação Nacional. Diário Oficial da União, Brasília, DF. <http://www. planalto.gov.br/ccivil 03/leis/L9394.htm>.

Caldart, R. S. (2009). Educação do campo: notas para uma análise de percurso. Trab. Educ. Saúde, Rio de Janeiro, v. 7 n. 1, mar./jun. p. 35-64.

Caldart, R. (2011). Por uma educação do campo: traços de uma identidade em construção. IN.: Arroyo, M., Caldart, R., Molina, M. (Orgs.). Por uma educação do campo. 5 ed. Petrópolis, RJ: Vozes.

Cardoso, M. B. da C.; Hage, S. M. (2017). Educação de Jovens e Adultos no ressignificar da formação docente e currículo na Amazônia brasileira. Revista Terceira Margem Amazônia. V. 2, n. 6. http//www.revistaterceiramargem.com/index.php/terceiramargem/article/view/107/95. Acesso em: 24 jan. 2022.

Escola Municipal de Ensino Fundamental Abraham Lincoln (EMEFAL). (2020). Dados de alunos matriculados entre 2003 e 2017. Escola Secretaria de Educação do município, Medicilândia.

Freire, P. (1996). Pedagogia da Autonomia: saberes necessários a prática educativa. São Paulo: Paz e Terra, 1996.

Gerhardt, T. E.; Silveira, D. T. (orgs.). (2009). Métodos de pesquisa. Porto Alegre: Editora da UFRGS.

Minayo, M. C. de S. (2008). O desafio do conhecimento: pesquisa qualitativa em saúde. São Paulo: Hucitec, 407p.

Oliveira, J.; Barreto, M. de L.; Litka, M. (2011). Tempo livre para o estudo e seu impacto na organização pedagógica em EJA. Florianópolis, SC: UFSC. V Encontro Brasileiro de Educação e Marxismo: Marxismo, Educação e Emancipação Humana.

Pará. (2009). Documento base nacional: Desafios da Educação de Jovens e Adultos no Brasil- Sujeitos da Educação de Jovens e adultos. http://forumeja.org.br/pa/node/5.

Rossini, M. A. (2001). Pedagogia Afetiva. 6.ed. Petrópolis, Rio de Janeiro: Vozes.

Santos, R.; Albuquerque, A. E. M. (2019). Análise das taxas de abandono nos Anos finais do ensino fundamental e do ensino médio a partir das características das escolas. In: $19^{\circ}$ Congresso Brasileiro de Sociologia, Florianópolis, SC.

Silva, F.V. da. (2017). Uma breve discussão sobre quem são sujeitos da EJA e quais suas expectativas na sala de aula. Trabalho de Conclusão de Curso. João Pessoa: UFPB/Centro de Educação. 44p. https://repositorio.ufpb.br/jspui/bitstream/123456789/11227/1/FVS30052018.pdf

Soares, L. (2002). Educação de jovens e adultos: Diretrizes curriculares nacionais. Rio de Janeiro: DP\&A.

Stoll, V. G., Bierhalz, C. D. K., Alves, S. S., Chaves, L. L., \& Castro, C. J. de. (2020). Reflections and perspectives for constituting the identity of students in Youth and Adult Education. Research, Society and Development, 9(12), e46791211348. https://doi.org/10.33448/rsd-v9i12.11348.

Tardif, M. (2002). Saberes docentes e formação profissional. Petrópolis: Vozes.

Tardif, M.; Lessard, C. (2004). O trabalho docente: elementos para uma teoria da docência como profissão de interações humanas. Tradução de João Batista Kreuch. 3. ed. Petrópolis, RJ: Vozes.

Tenório, W.; Formigosa, M., Rocha, C. G., \& Santana, R. (2019). A formação e atuação docente na disciplina de ciências em escolas do campo na Amazônia Paraense. Revista Insignare Scientia - RIS, 2(4), 158-179. https://doi.org/10.36661/2595-4520.2019v2i4.11021

Xavier, M. do P. do S. R., Seruffo, M. C. da R., \& Pires, Y. P. (2020). Analyze of persistence and school dropout in Youth and Adult Education: A case study in the Municipality of Castanhal-Pará. Research, Society and Development, 9(6), e190963481. https://doi.org/10.33448/rsd-v9i6.3481.

Yin, R. K. (2015). Estudo de caso: planejamento e métodos. 5 ed. Porto Alegre: Bookman. 